\title{
A LINGUAGEM DO DIZER EM UM CORPO QUE SE APRESENTA COMO ÉTICO
}

Magali Mendes de Menezes*

RESUMO - O objetivo deste texto é apresentar o movimento que vai de Totalité et Infini à Autrement qu'être au-delà de l'essence, ou seja, da diferença vista como separação absoluta entre Eu e o Outro, para uma diferença que atravessa a própria Subjetividade, uma diferença que passa a compor o tecido mesmo desta Subjetividade e, por sua vez, o tecido mesmo do próprio texto. O dizer não se apresenta aqui como um movimento verbal, mas é passividade extrema de exposição ao Outro. Podemos dizer que o Outro é anterior a mim, é ele que me chama a existência, não sendo então signo verbal, nem modalidade de conhecimento. Seu sentido está no fato de expor uma subjetividade ferida, desde sua origem pelo outro. O estrangeiro não é mais o Outro, mas sua condição de estrangeiro pertence a subjetividade, fazendo com que o sujeito deixe de ser contemporâneo de si mesmo.

PALAVRAS-CHAVE - Subjetividade. Diferença. Alteridade. Corpo. Dizer. Linguagem.
ABSTRACT - This paper has as its objective to show the movement that goes from the Totalité et Infini to Autrement qu'être au-delà de l'essence, that is, the difference seen as separation between $\mathrm{I}$ and the Other to a difference that crosses Subjectivity itself, a difference that makes the very tissue of this Subjectivity and, for that matter, the very tissue of the text itself. Saying doesn't present itself here as a verbal movement, instead it is the extreme passivity in exposition to the Other. We can say that the Other exists before me, he calls me to existence, so he is not a verbal sign, nor it is a knowledge modality. His meaning is in the fact that he exposes a wounded subjectivity since his origin in the other. By now, the foreign is not the Other, instead his condition as foreign belongs to the subjectivity, which makes the subject not be an acquainted to himself.

KEY WORDS - Subjectivity. Difference. Otherness. Body. Saying. Language.

Quando fui escrevendo este texto, fui me dando conta que pensar o Dizer era desafiar seu sentido, pôr em risco o que há de sagrado no próprio Dizer, fazendo da palavra escrita um lugar profano. Profano no sentido de violar o que parece ser um segredo, o que pertence a outro tempo, sempre imemorável, tempo que já passou. É o que diz Levinas quando comenta que discurso divulga e profana o indizível, abusando da linguagem; captando no Dito o indizível que o filósofo de alguma forma tenta reduzir. ${ }^{1}$ Este texto foi se construindo a partir de uma reflexão sobre o Dizer e a própria possibilidade de escrever sobre este Dizer. O texto e sua inspiração movimentam, desse modo, as palavras - palavras que se constroem na ambigüidade, pois a palavra é, ao mesmo tempo, o que extrapola o texto, vindo

FEEVALE, Novo Hamburgo

Cf. LEVINAS, Emmanuel. 1974, p. 52.

\begin{tabular}{|l|l|l|l|l|l|}
\hline VERITAS & Porto Alegre & v. 52 & n. 2 & Junho 2007 & p. 67-77 \\
\hline
\end{tabular}


sempre de fora, ofendendo a margem; mas também a possibilidade de preenchimento do espaço, interioridade da escrita que toma conta do sentido, risco do fechamento. Para Levinas,

a unidade do gênero é precisamente posterior à fraternidade. A proximidade é uma diferença - uma não-coincidência, uma arritmia no tempo, uma diacronia refratária a tematização - refratária à reminiscência que sincroniza as fases de um passado. O inenarrável! Outro perdendo na narração seu Rosto de próximo. Relação indescritível, no sentido literal do termo, inconvertível em história, irredutível a simultaneidade do escrito, ao eterno presente do escrito que registra ou apresenta resultados. ${ }^{2}$

Por isso escrever é sempre um risco (belo risco), mas risco necessário àquele que faz de seu texto uma resposta, palavra comprometida não apenas com a fala, mas com a escuta, saber que não tem a última palavra. Neste momento recupero a metáfora de Levinas sobre a respiração para trazê-la ao sentido da escrita. A inspiração do texto vem do Outro, uma ordem que exige uma resposta. Após vem a expiração do texto, que não é um esvaziamento do que já fora dito, mas a necessidade mesma de refazer, de recomeçar, de des-dizer-se (outramente dito). Por isso, este texto é descontínuo, foi se construindo na interrupção da própria palavra, as entrelinhas tornaram-se frestas, aberturas que permitiram a respiração da palavra para que o Outro pudesse, assim, invadi-la. Não como um ocupante, posseiro buscando um lugar fixo ou seguro para se instalar, mas o texto é permeado pelo estrangeiro, contagiando a palavra, que no encontro com o estranho, aprende e reaprende a falar.

A palavra caminha assim, no fio tênue, transparente e quase invisível do sentido originário que a inspira e que perpassa o presente do texto. A escritura aparece no silêncio do autor e no murmúrio do que dele se aproxima. A palavra nos conduz ao indecidível da fala (utilizando uma expressão de Derrida), à abertura escancarada do texto, para que possa Dizer. O Dizer passa a ecoar nas paredes das palavras que surgem como ditos, mas um dito que se trai. Aí se encontra, novamente, toda ambigüidade do Dizer, pois ao atravessar o dito, inspira a fala, mas também a transcende, causando um lapso no tempo, tornando toda fala diacrônica. Desse modo, o sentido não é apenas o que perpassa como também o que passa, ou seja, o que se faz passado. A temporalidade torna-se então, fundamental para compreendermos a linguagem. O "que passa" como diferimento - no sentido resgatado por Derrida ao referir-se à Diferença - mostra um tempo que só pode ser compreendido enquanto diacrônico. O "que passa" é tanto o que pertence a outro tempo, como uma passividade radical, daquele que sempre se julgou autor do mundo.

O movimento que aqui intecionamos percorrer é o movimento que vai de Totalité et Infini à Autrement qu'être au-delà de l'essence, ou seja, da diferença vista como separação absoluta entre Eu e o Outro, para uma diferença que atravessa a própria Subjetividade, uma diferença que passa a compor o tecido mesmo desta

Idem, p. 258. 
Subjetividade e, por sua vez, o tecido mesmo do próprio texto. O dizer não se apresenta aqui como um movimento verbal, mas é passividade extrema de exposição ao Outro. Podemos dizer que o Outro é anterior a mim, é ele que me chama a existência, não é então signo verbal, nem modalidade de conhecimento. Seu sentido está no fato de expor uma subjetividade ferida, desde sua origem pelo outro. Agora o estrangeiro não é mais o Outro, mas a estrangeiridade está presente na subjetividade, fazendo com que o sujeito deixe de ser contemporâneo de si mesmo.

A Subjetividade, dessa forma, carrega todo enigma do Dizer. O Dizer da Subjetividade acolhe a palavra do Outro, ou seja, a palavra do Outro se torna a voz do próprio Dizer. O entrecruzamento dessas duas dimensões - do Rosto do outro como palavra e da subjetividade como dizer - dá a linguagem um sentido ético. A palavra enquanto significação, que transcende o plano da manifestação, provoca no sujeito um movimento de transcendência, nos remetendo ao "passado" da Subjetividade, que nesse momento do encontro com o Outro se transforma em resposta. A palavra é, ao mesmo tempo, "recebida e ofertada". ${ }^{3}$ A palavra do Outro faz então, uma fissura no presente; ao carregar em si um vestígio desse passado, mostra que, de alguma forma, dele fez parte. O Dizer é, portanto, o acolhimento incondicional da palavra do Outro, antes mesmo de sua escuta.

O sujeito empírico (autônomo) é, assim, constantemente interrompido pelo sujeito ético (heterônomo). O sujeito, ao se perceber ferido pela presença do Outro, escuta uma fala que lhe parece familiar, não porque houvesse um a priori capaz de amenizar a originalidade desta fala. O que Levinas busca nos mostrar é que o acolhimento do Outro é anterior a sua presença concreta, pois a Subjetividade é feita de alteridade. O sujeito, quando se ergue, já está atingido pelo Outro e seu erguimento é já uma resposta ao passado que o atravessa enigmaticamente.

Isto é possível porque a subjetividade em Levinas é encarnada, possui um corpo ético, como se o Outro se encontrasse tatuado em sua própria pele, e a significação dessa presença se traduz através da maternidade - metáfora que carrega em si o sentido ético do Dizer. O corpo estremece com a presença do Outro, o sujeito é assim composto por uma multiplicidade pré-originária. A linguagem que tenta expressar essa trajetória deve ser em si transgressora, apresentando palavras que não são aprisionadas, por isso são capazes de serem metáforas, desafio de um tempo que se faz, fazendo-se Outro. A palavra torna-se escuta ensurdecedora do Dizer; e além de toda sonoridade, há um silêncio que ressoa, significação originária de toda fala. "A exposição ao outro é des-interessamento proximidade, obsessão pelo próximo, obsessão apesar de si, ou seja, dor. A dor não deve ser interpretada como uma ação sofrida, mas assumida", comenta Levinas. ${ }^{4}$ A dor vem da cumplicidade com a dor do Outro, e do movimento mesmo em tecer a palavra, pois como acrescenta Paulette Kayser, o texto de Levinas é um texto ferido, as palavras parecem chorar. O texto torna-se então a oferta da pala-

FERON, Etienne. 1992, p. 60.

LÉVINAS, Emmanuel. 1974, p. 92. 
vra, em que o dito se faz lugar (sempre passageiro) de renascimento, de compromisso com toda fala silenciada pela violência. Toda escrita é assim, inspirada pelo Outro, é já resposta, é já justiça. A linguagem sofre um estiramento, deve desdizer-se constantemente (esta é sua justiça), apresentando e desapresentando o que escapa a todo sentido, pretensamente, inaugurado pela consciência que se diz fundante de todo sentido.

Procurou-se, então, primeiramente mostrar, neste trabalho, que o sentido do Dizer atravessa o Rosto do Outro. "O dizer, ou seja, o Rosto, é o aviso de uma proposição inaudita, de uma insinuação", ${ }^{5}$ nos diz Levinas. Como palavra original, o Rosto no encontro do face a face, interrompe uma rotina, em que o sujeito ao absorver o mundo, neutraliza a diferença. Esse Rosto abala o universo seguro do $\mathrm{Eu}$, desacomoda o presente, pois não penetra nas cadeias conceituais que poderiam representá-lo. Toda representação está distante da apresentação, imediata por si mesma, do Outro. É desse modo que Levinas afirma a condição estrangeira do Outro exige do Eu um sair de seu lugar e ir ao encontro, sem a certeza do retorno. Em Totalité et Infini, Levinas refere-se sempre ao Rosto como uma exterioridade absoluta que transcende e transborda a totalidade do sistema, impossibilitando o enquadramento ou fechamento de qualquer análise que possa ser feita sobre o Outro. A totalidade se vê aqui ameaçada, é obrigada a abrir-se, contradizendo-se, pois admitir algo que não entra na totalidade é perceber que a totalidade não é total. A significação do Rosto é o Infinito, que produz uma linguagem cuja essência é sempre relação com Outro. O Rosto, por ser Infinito transborda toda idéia possível de representação e introduz no sujeito um Desejo, que Levinas chama Desejo Metafísico. Recuperando o esquema cartesiano sobre a idéia do infinito, percebemos um sujeito que através do desejo vai ao encontro do Outro. Não um desejo necessitante, que surge como uma necessidade de satisfação, mas um desejo sempre desejante, porque deseja o Infinito. Em Levinas não há satisfação possível no Desejo, deseja-se o próprio desejo. Deseja-se essa terra inabitada, a utopia, o não-lugar (pois todo lugar já seria ontológico) em que se encontra o Outro. O desejo não é de habitar, possuir o que escapa à posse, pois o não-lugar não pode ser habitado, não há posseiro legítimo. Não habitamos o desejo, mas o desejo nos habita, como um estranho/familiar incômodo, desassossego que nos move para o infinito, para o Outro. Fugir do desejo é fugir de nós mesmos, de nossa humanidade, pois o desejo é o que nos humaniza.

A transcendência, movimento do sujeito desejante, manifesta-se no excesso do Infinito em relação à totalidade, que reuniria em si as noções de identidade do eu, de objetividade e da história a partir da noção de um Mesmo. Na relação face a face, a distância não é jamais superada, mas é na distância que o encontro se efetua, em que nenhum dos membros dessa relação perde sua estrangeiridade. Diante do Outro, o eu também é estrangeiro e é essa condição de habitarmos lugares diferentes que faz com que a relação rompa com qualquer risco de totali-

LEVINAS, E. 1988, p. 105. 
dade ou síntese. Como comenta Levinas, "Pensar o infinito, o transcendente, o Estrangeiro, não é, pois pensar um objeto. Mas pensar o que não tem traços de objeto é, na realidade, fazer mais, ou melhor, do que pensar". ${ }^{6}$ Isso nos levaria ao desafio de um pensamento que não é mais solitário, a uma racionalidade que se obriga a rever-se, não mais a partir de si mesma, em um movimento endógeno, pois a provocação dessa revisão vem agora de "fora".

A palavra do Outro, ou seja, sua própria presença é acolhida incondicionalmente pelo Eu, sem precisar de qualquer mediação. Por isso, a palavra é verdade, carrega em si mesma seu sentido, prestando socorro a si. A verdade, portanto, não é uma verdade de representação. O sujeito recebe o Outro em sua indigência, em que a mais profunda miséria assume sua altura e exige resposta. A palavra é corpo, expressão daquele que sai do anonimato e vai narrando sua própria história. O "eis-me aqui" do Outro exige, contudo, uma resposta imediata. Assim, a resposta instaura o presente, em dilatação consigo mesmo, pois a resposta será sempre insuficiente. O presente deixa de ser provocado pelo exercício viril de uma racionalidade que, ao objetivar a diferença, buscava instaurar o sentido do que se apresentava, tornando-o presente à consciência.

O caminho de entrega incondicional ao Outro é árduo, pois tira o Eu de sua "felicidade", descrita por Levinas como estado paradisíaco, para mergulhar em uma relação que não nos apresenta nenhuma garantia de retribuição. Levinas traça um percurso que vai do Ser ao Outro, exterioridade que é capaz de abrir uma brecha na Totalidade, apresentando um sujeito que sai de seu universo de interessamento (pois o ser é acontecimento que produz os entes, e assim também se produz), para a entrega gratuita (sem interesse) ao Outro. É possível então, um acontecer que se dê fora do ser, em que a manifestação do ser não seja responsável por seu sentido - esse acontecimento é a presença do Outro desafiando todo e qualquer projeto de leitura e significação.

Mas o mundo, a sociedade, não é feito apenas de duas pessoas; há uma comunidade que gira em torno desta relação e que, de alguma forma, interfere na relação imediata do face a face. O terceiro perturba a intimidade dessa relação e introduz uma contradição que não pode apenas ser dita em termos éticos, mas necessita do político, jurídico e institucional. Com a presença do terceiro, Levinas faz surgir a questão da Justiça. A justiça exige medida, comparação, pois agora o Eu, sujeito do texto levinasiano, não está só diante do Outro, mas deve se perguntar "a quem agora é mais urgente responder? Quem é o mais próximo?". É preciso construir o espaço, definir o lugar para acolher a igualdade. Depois de falar da condição estrangeira, do deslocamento constante, do não-lugar, tanto do Eu que não se percebe mais mesmo; como do Outro que não possui um lugar fixo de determinação, Levinas retorna ao mundo do ser. Mas é importante observarmos que este retorno não sugere um abandonar tudo que até agora se teceu, mas em perceber um ser que também não é mais o mesmo; ou seja, um ser contaminado

\footnotetext{
LÉVINAS, E. 1961, p. 41.
} 
pela bondade. O ser, transfigurado, apresenta então uma outra face, em que o outramente que ser induz a um ser outramente. O Outro, mesmo sendo estrangeiro, é agora cidadão, sujeito de direitos; e a justiça visa a igualdade entre os sujeitos. O Estado de Direito surge como o Estado do Direito. O mundo da assimetria é substituído pela simetria que a justiça exige, e é nesse momento que poderíamos pensar que o Eu também será terceiro e próximo para alguém. Assim, a Justiça prolonga e atualiza a responsabilidade por outrem, não esquecendo que toda sua inspiração vem do Rosto. Ou seja, a justiça não se pode resumir a atos que voltem a massificar o outro, em que a lei em sua generalidade esqueceria a originalidade de toda e qualquer alteridade; a humanidade não pode perder seu Rosto. As instituições, representações do direito, devem constantemente se revisar, como ditos, respostas possíveis, mas ainda insuficientes ao Outro. A justiça não é, portanto, apenas o direito, mas o movimento incessante de responder ao Outro, capacidade de se desdizer. Acompanhamos assim, um sujeito que se vê "tocado" pelo Outro, sendo exigido a responder (não somente ao próximo, mas a todos os próximos), sem compreender, ao certo, de onde emerge esta obrigação.

Ao descrevermos essas passagens no pensamento de Levinas, podemos perceber uma reflexão que se movimenta entre a altura e a profundidade. O sujeito que é inspirado e, ao mesmo tempo, ordenado pelo infinito revela um além, mostrando um Rosto que é excesso, transbordamento que faz escorrer o infinito dos limites de toda possibilidade de totalização (por si só, totalitária). Mas este pensamento também nos conduz à profundidade, ao aquém do próprio sujeito, que não acompanhou seu início. Será na profundidade da subjetividade que a responsabilidade pelo outro ecoará. Tanto o além como o aquém vão apresentando o fio de um texto que vai se tecendo na tensão da própria linguagem. Que relação há entre o além do Rosto e o aquém da subjetividade? O que buscamos mostrar é que essa relação se encontra no sentido do próprio Dizer. O Dizer do Rosto toca o corpo da subjetividade, porque é vestígio de seu passado (ou seja, presença na ausência), tempo irrecuperável. Dizer, que ao ser desfiado nas idas e vindas do dito filosófico, a partir do Rosto que se apresenta, nos remete a um passado profundo que não pode ser mais recuperado. A inquietação provocada pelo Dizer do Rosto nos põe diante da memória da pele (e não mais da consciência) que nos faz sentir que o que "se passou" tece o "se" (soi) da subjetividade mesma. Na subjetividade o se é a passividade de uma pele exposta ao outro, que ao se esvaziar de uma identidade (pois não há ainda sujeito), se aproxima do Outro. O não-lugar da subjetividade é o lugar do outro, "hemorragia para o Outro". Deparamo-nos novamente com o esforço de falar daquilo que extravasa o dito e este esforço assume seus limites e sua carga na obra Outramente que ser ou além da essência. O problema central retorna e é incontornável, nesse momento preciso do texto, quando buscamos pensar a linguagem que seria capaz de aproximar-se deste Dizer. A linguagem fala na e a partir da ausência, isto não quer dizer uma ausência de linguagem, mas uma linguagem da ausência. Levinas, ao evitar a linguagem ontológica e eidética, põe em questão a força do ser (conatus essendi), para pensar, desse modo, uma linguagem que surja como passagem, uma linguagem como já nos referimos, 
metafórica. A própria palavra também é passagem, em seu nomadismo transforma o texto em um lugar invadido pelo tempo.

O Dizer, como linguagem original (nossa língua maternal! pois é a partir dela que aprendemos a falar), traz inspiração a todo discurso para que responda, não mais ao passado, mas ao presente. Discurso que não tem medo de ser interrompido, abandonando sua condição de monólogo seguro, para entregar-se (todo texto é assim uma entrega) ao Outro que já de alhures nos chega, sem pedir licença. O texto é entrecruzado pelo silêncio, caminho aberto para que o Outro possa falar. A Filosofia não pode esquecer que existe no desfazer da palavra uma tensão: não é o Dito que se dirige ao Dizer, buscando trazê-lo à luz, mas é o Dizer que, de alguma forma, se retrai (como num ato de bondade), para que o Dito possa surgir como resposta. Como comenta Levinas, o Dizer é, ao mesmo tempo, um dizer ao Outro e um "se dizer", exposição da pele, expor-se sem defesas ao Outro, isto é, responder pelo Outro. É assim que Levinas vai expondo uma subjetividade como substituição, que nos coloca em uma condição de refém do Outro, a ponto de sofrer em seu lugar. O corpo que traduz o sentido do Dizer, para-outro-apesar-de-mim, é maternal. O Feminino, metáfora possível para pensar a responsabilidade, recupera o corpo das mulheres para falar do sentido do humano. Partimos do sujeito viril (definido por Levinas como aquele que busca tudo dominar - e aqui é importante destacar como o faz Catherine Chalier, que Levinas é um dos poucos filósofos que define o sujeito de seu texto como masculino), que vai se fragilizando ao ser acolhido em sua Casa (já feminina) pela mulher, sujeito que ao encontrar-se com o Feminino, se efeminiza; para nos depararmos com uma subjetividade que é agora acolhedora (feminina em si mesma). É assim que Autrement qu'être... apresentarse-á como o livro do relaxamento da virilidade, da doença da identidade, da maternidade como análoga à própria subjetividade. O Feminino tornar-se-á um elemento fundamental para compreendermos tanto este processo de relaxamento vivido pelo sujeito, como a linguagem e o sentido mesmo do próprio Dizer. Estranha maneira de significar, pois o Feminino pode se apresentar como um desses termos indecidíveis sobre os quais comenta Derrida. Indecidível não pela impossibilidade de determinar seu sentido, mas porque seu sentido é múltiplo, ferindo em si mesmo o sentido de único, a distinção cartesiana do claro e do distinto. O Feminino é apresentado, em diversas passagens do texto de Levinas como equívoco, fragilidade, ambigüidade. É através do Feminino que Levinas fala da alteridade, do acolhimento, da excedência e da subjetividade.

O Feminino foi primeiramente compreendido como Casa. O sujeito perdido entre os elementos do mundo está sujeito ao desaparecimento. Esse sujeito ainda não está pronto, precisa construir uma interioridade, mostrar-se in-divíduo, estar definitivamente separado. O risco do anonimato o persegue e a incerteza do amanhã faz com que esse sujeito busque um abrigo. A Casa não é mais um elemento entre outros, um prédio frio, mas ela possibilita a intimidade, pois é, desde já, acolhimento. A Casa é hospitaleira porque é feminina. Como em um 'útero' agora o sujeito está seguro e é capaz de se construir plenamente. Levinas, nessa relação íntima (e de intimidade) entre a Casa e o Feminino acrescenta que o Feminino é 
apenas uma dimensão da morada e não necessitaria da Mulher concreta para aí se dar. O Feminino é o acolhimento por excelência.

Mas o Feminino é também Mulher, o Outro concreto que está na Casa. Um Outro cuja presença é discreta, quase uma ausência, efetivando o acolhimento que a Casa potencializa. No Eros, a fenomenologia realiza seu movimento sem se completar, o Feminino inaugura uma relação nova que exige conseqüentemente, uma nova postura daquele que se coloca como Mesmo. O Feminino é aquele que "se apresenta sem se apresentar", enunciado que se torna absurdo a uma consciência acostumada com a lógica da coerência. "A simultaneidade ou equívoco dessa fragilidade e desse peso de não-significância, mais pesado que o peso do real amorfo, nós chamamos feminidade". ' Ao mesmo tempo que a Amada surge, ela também se retira, seu modo de existência é uma fuga à luz, como se habitasse o obscuro (trevas). Assim, a Amada desafia, faz o convite a uma outra relação tanto erótica como racional. O toque não toca uma pele para se apropriar, visando ao prazer do presente, tornando o Outro objeto de desejo. O toque conduz os amantes ao futuro, ao que ainda não é, «um menos que nada»). Pensar a Amada além do objeto e do Rosto não é pensar alguém que não tenha um Rosto, mas é estar diante de alguém que não nos remete nem a nós nem a ela mesma, porém a um além. O Feminino, enquanto Amada, está para além do Rosto, pois apresenta uma excedência em si mesmo. O encontro com o Feminino é o próprio desencontro, em que se busca um outro que não pode nunca estar aí. Levinas chega a comparar o erótico ao il y a, da noite que se faz no anonimato. A noite do erótico esconde o mistério do que não pode ser violado e conserva, por isso, sua virgindade. Tocar o Feminino é, desde já, profaná-lo! O Feminino, que é noite, quase il y a, portanto amorfo, não tem o estatuto de ente, não é nomeável, e podemos ainda dizer, nem humano. Entre o animal e a criança, a Amada deixa seu estatuto de pessoa. Poderíamos dizer que a Fenomenologia da carícia descrita por Levinas, a partir da relação com o Feminino inaugura uma reflexão que será desenvolvida em toda sua obra, mesmo que essa terminologia seja depois abandonada. O dito filosófico "toca" o Outro em sua ausência, como uma carícia que não quer e não pode apropriar-se da pele do Outro, como uma palavra que não aprisiona.

Rosto, que é diferente a ponto de ser adjetivado como Rosto Feminino, quando se olha no espelho, não se vê mais. Perdida em sua própria animalidade, portanto sujeita à natureza, o Feminino segue seu destino natural: gerar o outro e não a si. Equivocidade extrema daquela que parece não querer crescer, por isso está entre a criança e o animal, ambos sujeitos a seus instintos, entregues ao tempo, apenas vivendo. Vida de irresponsabilidade, não aberta ao social, vida que se faz na intimidade não necessitante de linguagem, excluindo o terceiro. A Amada deixa o Amado sem palavras. O Feminino é então o equívoco por excelência.

A Mulher (Feminino encarnado) é o equívoco da linguagem, que ao invés de dizer, faz calar. Sua presença na ausência anuncia o silêncio que é capaz de dizer

LÉVINAS, E. 1961, p. 287. 
mais do que qualquer palavra, pois, como comenta Zoltán Popovics, "o absolutamente outro é sempre o próprio silêncio, porque é inacessível e inapreensível. Mas o silêncio, esta ausência, é sempre o equivoco do silêncio, o equívoco da nãosignificância, em que o silêncio fala". . Assim, em sua condição de passagem, a mulher conduz ao futuro que é Outro. Não é nela que se realiza a ética (pois o universo erótico é ainda ontológico), mas através dela, que o terceiro - filho - tira os amantes de seu egoísmo erótico para abrirem-se à Justiça, como concretude ética. O Feminino, que enquanto Casa, possibilita a interioridade; enquanto Mulher é responsável pela exterioridade do Eu (viril). Diante do Rosto da mulher, a fecundidade se abre e o Amante se dirige ao Outro que não é mais ele mesmo, mas outro completamente outro - a exterioridade se chama agora Filho e a maternidade é a partir daí subsumida, como se na maternidade o filho fosse imanência e na paternidade fosse transcendência. A paternidade revela uma perpetuação do pai, mas ao mesmo tempo, um diferimento, em que o filho realiza a alteridade do pai.

Se o amante se transcende através do filho, como a mulher, agora mãe, pode realizar a sua transcendência? Deixando certamente de ser "Rosto Feminino" para ser apenas Rosto, em que o traço da feminidade não apareça mais. O Rosto é então dessexualizado e passa a ser Rosto (maiúsculo) porque pode ser qualquer um e todos ao mesmo tempo, contém em si a singularidade e universalidade.

A linguagem da mulher, por ser silenciosa não ensina, rompe com a "tagarelice" da consciência, que a tudo quer entender e desvelar. Uma nova relação se faz, que é desfalecência do ser e fonte da doçura em si. A mulher inaugura uma relação diferente de todas as relações que o homem até então construíra. O ser, sempre compreendido como essência, que invade e define todas as coisas, se encontra ferido em seu movimento pelo Feminino. Mas sua ferida é doçura, como se o Feminino penetrasse lentamente o domínio do ser para lhe mostrar um "outramente que ser". Não há violência, não há fala, apenas um silêncio daquela que não precisa se exibir para mostrar que está aí. O Feminino é uma presença discreta, quase inexistente, mas que em sua "insignificância" é capaz de anunciar a verdadeira significância.

A partir dessas análises, percebemos então que a Maternidade revela a ambigüidade mesma da ausência da mulher, pois quando a maternidade se realiza concretamente, a mulher desaparece; e quando se coloca como metáfora na subjetividade pronunciada como maternal, o corpo aqui Feminino se torna o sentido da ética, mas a maternidade passa a se realizar somente na palavra (metáfora). Enquanto na paternidade o Eu ainda sobrevive no Outro (filho), na maternidade não há mais nenhuma possibilidade de retorno.

O Feminino surge também como linguagem, a maternidade é a metáfora possível para falar da Subjetividade. A metáfora é a palavra que não significa, seu sentido não se encontra nela mesma, mas é palavra que reenvia a ausência, ao

HOPPENOT, Eric, 2004, p. 262. 
mais profundo passado. A palavra não se apropria de um sentido, mas torna-se expressão de passagem, um entre. Assim, o corpo da mulher fala mais que ela mesma. Sua linguagem, no entanto não é de palavras, mas de uma significância além do ser, da essência e de toda consciência. A subjetividade parte do Corpo e não do Logos, mesmo que necessite do logos para dizê-lo, o corpo é a linguagem que precede a língua, lugar (ou não-lugar) onde habita a ética. Corpo que é capaz de Dizer o que a mulher não diz, pois arraigada à intimidade da relação erótica, assemelha-se ao Tu familiar e não ao Vós que é altura. O dizer da subjetividade é Feminino, porque sua significação aproxima-se do sentido do próprio Feminino descrito por Levinas em outras passagens de seu texto. Embora não utilize mais o termo Feminino, a subjetividade é invadida pelo sentido mesmo do Feminino, ou seja, equívoco, ambiguidade, silêncio, retirar-se para o outro surgir. Como se o Feminino trouxesse à tona a memória do corpo, a linguagem da ambigüidade e o sentido mesmo da hospitalidade. O que é Feminino se faz Feminino sem dizê-lo. Não é mais a Casa (dimensão do Feminino) que hospeda o Outro, é o próprio corpo que acolhe a alteridade, flagrando uma identidade já doente em si mesma. A pele está entre a exterioridade e a interioridade, é uma abertura provocada pelos poros que respiram, não mais a si mesmo, mas o outro. O corpo é assim habitado pelo estrangeiro. A subjetividade não mostra apenas uma pele exposta ao Outro, mas a exposição desta exposição, o que Levinas chama de significância primeira, responsável por todas as outras significações. Corpo, que é passividade mais passiva que toda passividade, nos faz pensar em um corpo que é arrancado de sua inércia para ser materno. Como o corpo estéril de Sara, Rebeca, Raquel, entre outras mulheres citadas no Antigo Testamento. A maternidade surge então da incapacidade de gerar, da esterilidade humana.

Mas, quando pensamos o Feminino enquanto desfalecência, deveremos também pensar que este também é o destino das mulheres, se retirarem para que o outro possa nascer, morrer um pouco em si mesmas? Deveríamos então louvar a história de tantas mulheres ameaçadas pelo esquecimento, pela morte de seus nomes, em nome de uma transcendência que elas, por serem mulheres, não são capazes de participar? Presa à intimidade e à Casa, a mulher faz de si mesma a possibilidade do nascimento do Outro. Estranha combinação de fragilidade e força, pois o Feminino é o primeiro a ser capaz de abalar a força do logos, de apresentar ao homem outro mundo onde se é capaz de amar aquele que não se vê. Mas o faz não pela violência e sim pela capacidade de se retirar, de dar lugar ao Outro - atos extremos de compaixão. Assim, o Feminino não seria somente uma en-ergia ${ }^{9}$ que atravessaria o humano, mas adjetivo da mulher. No entanto, em uma entrevista com Philippe Nemo (1982), anos após a publicação da obra Autrement qu'être, Levinas muda esta posição comentando que o Feminino e o masculino seriam características próprias de todo ser humano, e não de um sexo ou gênero em especial.

"A familiaridade é um cumprimento, uma én-ergie da separação». Cf. Totalité et Infini, p. 166. 
Pensar a Ética além do ser seria então, justamente, desfazer os papéis culturalmente consagrados, ultrapassar o que se essencializou, não impondo nenhum adjetivo ao Outro (mesmo que esse outro seja mulher). No mesmo ano a publicação desta entrevista, Chalier questiona se Levinas não estaria cometendo um equívoco ao nomear o silêncio, a morada e o desfalecimento do ser como Feminino. Vocábulo que, por sua vez, não é neutro e que acaba sendo diretamente associado às mulheres (como o faz Levinas em passagens de seu texto).

E, para concluirmos, queremos ressaltar que a maternidade, como expressão mesma dessa Substituição, é uma linguagem que se faz no Feminino, que não é negação de nenhum sujeito, mas afirmação da alteridade, anunciando o sentido da ética. O Feminino seria, desse modo, mais que Casa, interioridade, Mulher - o Feminino seria a única linguagem possível para expressar a força e gratuidade do Dizer. É preciso que o próprio texto seja esse lugar de passagem, que a palavra carregue o outro, que a escrita seja maternal. O Dizer se faz então nossa língua maternal. O corpo Feminino nos conduziria, também, a refletirmos sobre o Feminino no corpo do texto, na abertura ética da escrita, na linguagem do Dizer, inspiração primeira de todo dito. A escrita teria um corpo Feminino, feito de aberturas, lugares de passagem, onde é possível ouvir a voz do outro.

O Feminino está, portanto, além do contraponto com o masculino, fazendo surgir uma subjetividade, um texto e um corpo feito na pluralidade.

\section{Referências}

CHALIER, Catherine. Figures du Féminin, lecture d'Emmanuel Lévinas. Paris: La nuit surveillée, 1982. FERON, E. De l'idée de transcendence à la question du langage, itinéraire philosophique de Levinas. Grenoble: Jérôme Millon, 1992.

KEISER, Paulette. Emmanuel Levinas: la trace du féminin. Paris: PUF, 2000.

HOPPENOT, Eric.L'oeuvre du feminine dans l'écriture de Maurice Blanchot. Grignan: Complicités, 2004.

Levinas, Emmanuel. Totalité et Infini, essai sur l'ext'riorité. Paris: Martinus Nijhoff, 1971. . Autrement qu'être au-delà de l'essence. Paris: Martinus Nijhoff, 1974.

En Découvrant l'éxistence avec Husserl et Heidegger. Paris: Vrin, 1988.

De l'existence à l'existant. Paris: Vrin, 1986

.Éthique et Infini. Dialogues avec Philipe Nemo. Paris: Librairie Arthème, Fayard et Radio France, 1982. 